\title{
Cardiomiopatía de Takotsubo
}

\section{Sr. Director:}

He leído con interés la revisión de Obón Azuara et $\mathrm{al}^{1}$ sobre la cardiomiopatía de Takotsubo (CTK) publicada en la Revista de Medicina Intensiva. Los autores comentan que «con su rápido reconocimiento se puede evitar la administración fútil de agentes fibrinolíticos y la realización de cateterismo en la fase aguda» y que «el empleo de los criterios diagnósticos basados en su presentación clínica facilita su sospecha y rápido reconocimiento para diferenciarlo del infarto agudo de miocardio (IAM)». Estas afirmaciones requieren algunas matizaciones:

1. La CTK es una enfermedad rara caracterizada por la aparición súbita de síntomas torácicos agudos asociados a cambios electrocardiográficos (elevación del segmento ST hasta en el $90 \%$ de los casos) que simulan un IAM, a mínima elevación de las enzimas cardíacas, a ausencia de lesiones angiográficas coro- 

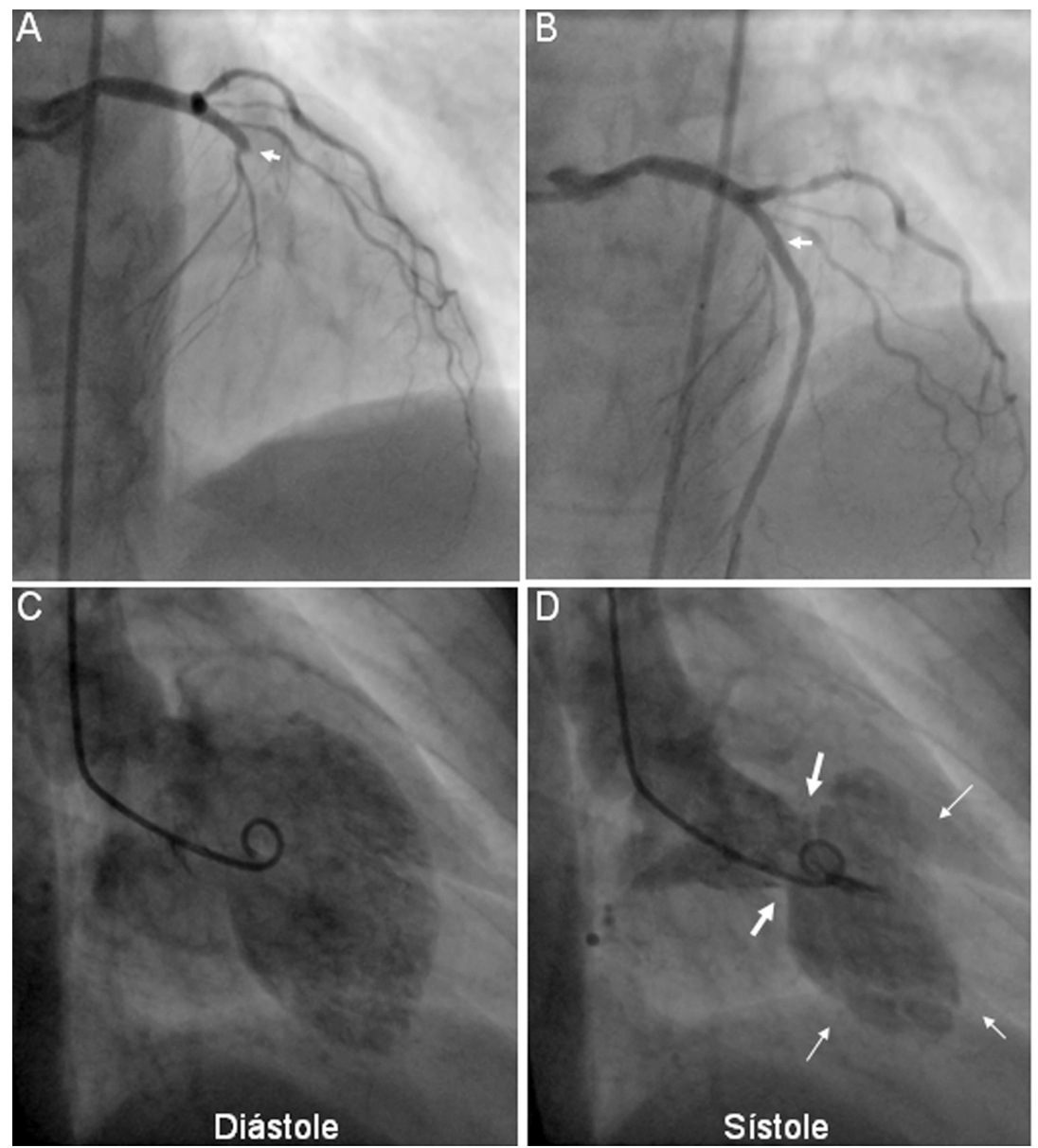

Figura 1. Mujer con dolor torácico y elevación anterior del segmento ST. Panel superior: arteriografía coronaria mostrando una oclusión total de la arteria descendente anterior izquierda en su porción media (A) y su recanalización posterior mediante angioplastia primaria (B). Panel inferior: ventriculografía izquierda mostrando imágenes en diástole $(C)$ y en sístole $(D)$ con dilatación ampollosa persistente de la punta (flechas).

narias y a aquinesia apical del ventrículo izquierdo (silueta ventriculográfica con ápex redondeado y cuello estrecho) que desaparece varias semanas después del acontecimiento agudo ${ }^{2,3}$. Así, los criterios diagnósticos de CTK basados en su presentación clínica carecen de validez al no poder descartar con certeza un IAM y, por tanto, no deben condicionar el tratamiento. Tanto el sexo (la mayoría mujeres), como la edad (entre 50 y 70 años), y los desencadenantes (estrés emocional o fisiológico), son tan comunes en ambos procesos que pierden toda validez discriminatoria ${ }^{1}$.

2. Un diagnóstico definitivo de CTK nunca puede realizarse en la fase aguda, pues un requisito indispensable es la transitoriedad (desaparición) de la disfunción ventricular apical varias semanas después del evento.

3. Administrar tratamiento fibrinolítico o realizar un cateterismo cardíaco urgente a un paciente con malestar torácico y elevación del segmento ST es oportuno, y nunca fútil, aunque luego (retrospectivamente) se haga el diagnóstico CTK. Es más inadecuado diagnosticar los frecuentes IAM con elevación del segmento ST como CTK, que diagnosticar las infrecuen- tes CTK como IAM. En el primer supuesto los pacientes con IAM no reciben el oportuno tratamiento de reperfusión (fibrinólisis o angioplastia primaria), lo que incrementa su mortalidad ${ }^{4}$. En cambio, en la segunda alternativa, aunque los pacientes con CTK pueden recibir un fármaco fibrinolítico, se asegura el tratamiento adecuado de la mayoría de los IAM con elevación del ST. Una angiografía coronaria precoz, en los Servicios que la tengan disponible las 24 horas del día, podrá diferenciar ambos procesos y, ante la visualización de un árbol coronario normal, evitar la administración de tratamiento fibrinolítico y sospechar una CTK en presencia de aquinesia apical.

4. La detección de una aquinesia apical en un paciente con dolor torácico y elevación del segmento ST requiere una angiografía coronaria que diferencie una posible CTK (árbol coronario normal) de un IAM con elevación del segmento ST, usualmente debido a la obstrucción total de una arteria descendente anterior izquierda larga que rodea la punta del corazón (wraps around) e irriga parte de la pared inferior del ventrículo izquierdo (fig. 1) . 
En síntesis, toda molestia torácica aguda asociada a elevación del segmento ST requiere decidir rápidamente si nos hallamos ante un IAM que necesita reperfusión. En estas circunstancias agudas, los síntomas de la CTK carecen de protagonismo en el diagnóstico diferencial.

J. ORTEGA CARNICER

Servicio de Medicina Intensiva. Hospital General de Ciudad

Real.

\section{BIBLIOGRAFÍA}

1. Obón Azuara B, Ortas Nadal MR, Gutiérrez Cía I, Villalón Anadón B. Cardiomiopatía de Takotsubo: disfunción transitoria apical de ventrículo izquierdo. Med Intensiva. 2007;31:146-52.

2. Kurisu S, Sato H, Kawagoe T, Ishiharu M, Shimatani Y, Nishioka K, et al. Tako-tsubo-like left ventricular dysfunction with ST-segment elevation: a novel cardiac syndrome mimicking acute myocardial infarction. Am Heart J. 2002:143:448-55.

3. Akashi YJ, Nakazawa K, Sakakibara M, Miyake F, Koike H, Sasaka K. The clinical features of Takotsubo cardiomyopathy. Q J Med. 2003;96:563-73.

4. An international randomized trial comparing four thrombolytic strategies for acute myocardial infarction. The GUSTO investigators. N Engl J Med. 1993;329:673-82.

5. Ibáñez B, Benezet-Mazuecos, Navarro F, Farre J. Takotsubo syndrome: a Bayesian approach to interpreting its pathogenesis. Mayo Clin Proc. 2006;81:732-5. 